Int. J. Electrochem. Sci., 11 (2016) 2854 - 2876

\title{
Electrochemical Properties of Chlorogenic Acids and Determination of Their Content in Coffee Using Differential Pulse Voltammetry
}

\author{
Ivana Tomac, Marijan Šeruga* \\ Department of Applied Chemistry and Ecology, Faculty of Food Technology, University of Osijek, \\ Franje Kuhača 20, HR-31000 Osijek, Croatia \\ *E-mail: marijanseruga@gmail.com
}

doi: $10.20964 / 110402854$

Received: 11 January 2016 / Accepted: 6 February 2016 / Published: 1 March 2016

\begin{abstract}
The electrochemical properties of nine chlorogenic acids (CGAs) isomers: three caffeoylquinic acids, CQAs (5-CQA, 4-CQA, 3-CQA), three dicaffeoylquinic acids, diCQAs (3,4-diCQA, 3,5-diCQA, 4,5CQA) and three feruloylquinic acids, FQAs (5-FQA, 4-FQA, 3-FQA) were studied by differential pulse voltammetry (DPV) method. The study has shown that electrochemical properties of CQAs and diCQAs are strongly dependent on their chemical structure and electronic properties, particularly on presence of electron-donating $-\mathrm{OH}$ and $-\mathrm{CH}=\mathrm{CH}-$ groups, and a strong electron-withdrawing effect of ester $(-\mathrm{COOR})$ group presented in their structures. The electrochemical properties of FQAs were additionally influenced by the presence of methoxy group $\left(-\mathrm{OCH}_{3}\right)$ attached on the aromatic ring. DPV measurements show that electrochemical oxidation of CQAs and diCQAs at a GCE is reversible, $\mathrm{pH}$ dependent, two- electron-two- proton process occured on catechol moiety in the structure of these molecules. Electrochemical oxidation of FQAs proceeded by an EC mechanism. In the first, electrochemical oxidation step, a phenoxy radical was formed by irreversible one-electron-one-proton process. In the second, chemical step, phenoxy radical undergoes hydrolysis generated a new more electroactive compound with methoxy-catechol moiety in the structure. This compound was reversible oxidised to methoxy-ortho-quionone structure by two-electron-two-proton process. The electrochemical properties of 5-CQA (main CGAs in coffee) were investigated more in detail. It was observed that anodic oxidation peak current of 5-CQA show its maximum in PBS solution of $\mathrm{pH} 7$ and linear relationship within the concentration range of $5-50 \mu \mathrm{mol} \mathrm{L} \mathrm{L}^{-1}$, with $\mathrm{LOD}$ of $1.2 \cdot 10^{-6} \mathrm{~mol} \mathrm{~L}^{-1}$. DPVs of coffee show that electrochemical properties of coffee extracts were very similar to that of investigated CGAs. Therefore, DPV was used for characterization of CGAs in coffees. It was shown that DPV is a very sensitive and selective method for determination of total CGAs content in coffee.
\end{abstract}

Keywords: Electrochemical properties, Chlorogenic acids, DPV, Coffee, Total CGAs content 


\section{FULL TEXT}

(C) 2016 The Authors. Published by ESG (www.electrochemsci.org). This article is an open access article distributed under the terms and conditions of the Creative Commons Attribution license (http://creativecommons.org/licenses/by/4.0/). 